\title{
Coronary arteriographic findings in black patients and risk markers for coronary artery
}

\section{disease}

\begin{abstract}
Coronary arteriographic results are reported in 1535 black patients: 751 men (mean age $57 \pm 11$ ) and 784 women (mean age $59 \pm 11$ ). Among the black men 19\%, 15\%, 21\%, and $4 \%$ had single-, double-, and triple-vessel and left main disease, respectively. Among the black women there were $12 \%, 10 \%, 15 \%$, and $3 \%$ with similar involvement. Logistic regression models showed that most of the recognized risk factors were positively correlated with significant (at least one artery with $\geq 50 \%$ stenosis) coronary disease, but a history of hypertension was not a significant independent predictor in either sex. ECG evidence of previous infarction increased the odds of detecting significant coronary disease by the greatest amount when controlling for other significant risk markers in women. In men both previous infarction and atypical pain (negative) were equally important. This study confirms but does not explain previous reports that have revealed less than expected angiographic evidence of significant coronary artery disease in black compared with white persons. (AM HEART J 1994;127:552-9.)
\end{abstract}

Reginald L. Peniston, MD, Lucile Adams-Campbell, PhD, John W. Fletcher, BS, Eric C. Williams, MD, Charles Murigande, PhD, Ernest Mensah, MS, Michael D. Crittenden, MD, and James A. Diggs, MD Washington, D. C.

Before the widespread availability of coronary arteriography, black persons were thought to have a very low incidence of angina pectoris or coronary artery disease. ${ }^{1}$ Case-control studies of coronary angiography have consistently shown that the black population in the United States has a lower prevalence of detectable coronary artery disease than what is usually found in white persons..$^{2-8}$ These angiographic findings seem to be inconsistent with the now generally accepted view that the coronary artery disease mortality rate is nearly equal in black and white men and is increased in black women as compared with white women. ${ }^{9,10}$ This inconsistency exists despite the presence of significant risk factors in blacks. ${ }^{11}$

\footnotetext{
From the Divisions of Cardiothoracic Surgery and Epidemiology and Can cer Control, Howard University Hospital and Howard University College of Medicine.

Supported by grant HL47208 from the National Heart, Lung, and Blood Institute, National Institutes of Health, Bethesda, Md. (Dr. Adams-Campbell), and grant 2G12-RR-03048 from the National Institutes of Health (Dr. Murigande).

Received for publication Jan. 7, 1993; accepted July 16, 1993.

Reprint requests: Reginald L. Peniston, MD, Division of Cardiothoracic Surgery, Veterans Administration Medical Center, 50 Irving St., NW, Washington, DC 20422.

Copyright 1994 by Mosby-Year Book, Inc

$0002-8703 / 94 / \$ 3.00+0 \quad \mathbf{4} / \mathbf{1} / \mathbf{5 1 7 9 1}$
}

This apparent contradiction may be the result of various categories of case selection bias as discussed by Pearson. ${ }^{12}$ The most pertinent in this setting is "prevalence-incidence" bias, possibly because of higher death rates for ischemic heart disease occurring outside of the hospital. ${ }^{13-15}$ Cooper and Simmons ${ }^{16}$ also provide convincing evidence based on epidemiologic and hospital discharge data that excessive noncoronary artery disease deaths in blacks are linked to hypertension and this phenomenon provides one mechanism by which blacks are omitted from at-risk populations referred for coronary angiography. "Detection-signal" bias ${ }^{12}$ may also be triggered by the association of hypertension with chest pain syndromes, ${ }^{17,18}$ independent of stenotic epicardial coronary artery disease. There are other possible sources of sample bias in comparisons of black and white populations; for example, several reports suggest the presence of nonmedical criteria such as socioeconomic or cultural factors in the selection of patients studied. ${ }^{19-22}$ These unresolved issues are relevant to debates on the subject of premature or excessive deaths from heart disease among blacks. The following retrospective review from a single laboratory was undertaken because the predominant clinical experience was overwhelmingly black and contributed significantly to the number of 
black patients thus far reported. In addition, the results of this review may offer a clarification of the unlikely sources of bias inasmuch as it represents the selection and study of black patients by black and other minority physicians.

\section{METHODS}

Medical data base. Available cardiac catheterization reports for the years 1983 through 1990 were retrospectively reviewed at Howard University Hospital, a private university teaching hospital serving the Washington, D.C. metropolitan area. Census data indicate that the communities served by Howard University Hospital are approximately $25 \%$ to $85 \%$ black. Yearly hospital discharge rates have averaged more than $95 \%$ black since 1910. All cardiologists who use the Howard University Hospital catheterization laboratory are representatives of black or other minority groups. Reports from patients undergoing coronary angiography to exclude or confirm a diagnosis of coronary artery disease were screened. Use of the data collected was approved by the internal review board of the institution. Inpatient medical records were not used for this study, and therefore no socioeconomic or other discharge abstract data were available. Catheterization laboratory registers indicated that 3427 coronary angiograms were obtained during the 8-year period included in this study. Data from studies showing incomplete angiograms, significant or primary valvular disease, congenital heart disease, previous bypass surgery, all repeat studies, and repeat angiography performed for concomitant therapeutic interventions (195 angioplasties, 16 intracoronary thrombolyses) were excluded. No attempts were made to document or retrieve missing reports. Data were collected in coded form, tabulated, and entered into a computerized data base. Demographic information, patient histories, and hemodynamic data were taken exclusively and directly from the official reports. Mention of hypercholesterolemia, hypertriglyceridemia, or hyperlipidemia was included as a single variable under "lipid elevation." All other risk factors were tabulated as present if they were specifically mentioned in the dictated histories. These included hypertension, diabetes, smoking (ever), family history, history of myocardial infarction (remote or recent), congestive heart failure, and dyspnea or shortness of breath. Pain was coded as absent, typical, or atypical if specifically described as such. $\mathrm{Pa}$ tients with typical and atypical pain were regarded as typical. Risk factors not mentioned were regarded as absent. ECG findings of infarction or left ventricular hypertrophy were abstracted as dictated in the catheterization reports, and there were no separate reviews of ECGs. Absent ECG findings were coded as missing data.

Angiographic definitions. Angiographic descriptions of coronary lesions were regarded as positive for any stenosis of $\geq 50 \%$. If a range of stenosis was reported (e.g., $40 \%$ to $50 \%$, the higher estimate was accepted. Variables were created for the left main, proximal left anterior descending, middle left anterior descending, any diagonal vessels, any circumflex, marginal, or ramus intermedius, and any right coronary artery or posterior descending artery. Single-vessel groups included any combination of left anterior descending and diagonal vessels, ramus or marginal, and right or posterior descending arteries. Single-, double-, or triple-vessel disease, or their combinations with left main disease, was calculated as the sum of these anatomic "regions." Body mass indexes defined as weight (kilograms) divided by height (meters) squared were calculated from height and weight entries contained in catheterization reports. Ejection fractions that were reported as "normal" (approximately one fifth of patients) but not quantified were recorded as $50 \%$. All other continuous variables that were absent were treated as missing data.

Statistical analysis. Comparisons between patient groups (black men and black women) were made by means of unpaired two-tailed $t$ tests for continuous variables. Tests for equality of variances were routinely performed before results of the appropriate $t$ tests were reported. The frequency distributions of noncontinuous variables were compared by means of chi-square contingency tables.

To describe the relationship between coronary artery disease and a set of explanatory predictor variables (i.e., age, hypertension, diabetes, smoking, family history, or lipid levels), stepwise logistic regression analyses were performed by means of the LOGIST procedure ${ }^{23}$ All odds ratios and results are reported from final models selected after backward elimination of independent variables. The univariate and multivariate statistical analyses reported in this article were performed with mainframe and $\mathrm{PC}$ versions of SAS software (Statistical Analysis System of SAS Institute, Inc.). Quantitative results are expressed as means \pm 1 standard deviation. $p$ Values less than or equal to 0.05 were considered significant.

\section{RESULTS}

From a total data base population of 1623 patients, there were 1535 black patients including 751 men and 784 women. Tables I and II show that the men and women differed greatly with regard to risk factors and outcome variables. Black men were on average younger and less obese than black women. There was a significantly greater proportion of men with a smoking history and evidence of a previous myocardial infarction. Men did not differ from women with regard to family history, lipid abnormalities, dyspnea and shortness of breath, or congestive heart failure. Pain symptoms were significantly and differently apportioned, inasmuch as women had a greater prevalence of atypical pain syndromes. The women had significantly less coronary artery disease in all categories and a higher systolic blood pressure and ejection fraction as measured in the catheterization laboratory.

Tables III and IV display differences within sex groups in patients with and without significant coronary artery disease. These univariate analyses show 
Table I. Patient characteristics of black men and women undergoing coronary angiography

\begin{tabular}{lcc}
\hline \multicolumn{1}{c}{ Characteristics } & $\begin{array}{c}\text { Males } \\
(n=751)\end{array}$ & $\begin{array}{c}\text { Females } \\
(n=784)\end{array}$ \\
\hline $\begin{array}{l}\text { Hypertension* } \\
\text { Diabetes } \dagger\end{array}$ & 69 & 77 \\
Smoking (ever) $\ddagger$ & 23 & 34 \\
Family history & 62 & 37 \\
Lipid elevation & 26 & 31 \\
History of infarction $\ddagger$ & 17 & 19 \\
ECG evidence of in- & 28 & 18 \\
farction $\ddagger$ & 24 & 11 \\
ECG evidence of & 24 & 19 \\
LVH $\dagger$ & & \\
Chest pain $\ddagger$ & & \\
$\quad$ None & 16 & 9 \\
$\quad$ Atypical & 12 & 16 \\
Typical & 72 & 75 \\
DOE or SOB & 37 & 9 \\
Congestive heart fail- & 10 & \\
ure & & $59( \pm 11)$ \\
Age (yr) $\dagger$ & $57( \pm 11)$ & $30( \pm 7)(\mathrm{n}=451)$ \\
BMI (kg/m $\left.{ }^{2}\right)^{*}$ & $28( \pm 5)(\mathrm{n}=441)$ \\
\hline
\end{tabular}

$B M I$, Body mass index; $C H F$, congestive heart failure; $D O E$, dyspnea on exertion; $L V E D P$, preangiographic left ventricular end-diastolic pressure; $L V H$, left ventricular hypertrophy; $S O B$, shortness of breath.

Values are percentages unless otherwise indicated.

${ }^{*} p<0.01$.

$\dagger p<0.05$.

$\ddagger p<0.001$

significant differences between men with and without coronary artery disease for the presence of diabetes, lipid abnormalities, previous infarctions, atypical pain, age, left ventricular end-diastolic pressure, and ejection fraction. There were no significant differences with regard to history of hypertension, smoking (ever), or congestive heart failure, whereas these variables were significantly different in black women with regard to coronary disease. Although body mass index was inconsequential in relation to coronary disease in men and women, there was a tendency for women with coronary disease to be less obese $(p=0.0595)$. Women also showed a correlation between increased systolic pressure (slightly elevated) and decreased diastolic pressure (normal range) with the presence of coronary disease. Table $\mathrm{V}$ shows that among patients with established coronary artery disease, the degree of involvement as measured by the number of vessels was not significantly different between men and women.

Stepwise logistic regression analyses were carried out to assess the relative explanatory value of variables predictive of coronary artery disease (at least one vessel with $\geq 50 \%$ stenosis) in black men and black women separately (Tables VI and VII). Most notably these regressions confirmed the usual associations with standard risk factors for coronary disease
Table II. Cardiac catheterization and coronary angiographic findings in black men and women

\begin{tabular}{lcc}
\hline \multicolumn{1}{c}{ Findings } & Males & Females \\
\hline $\begin{array}{l}\text { Right dominance } \\
\text { Vessels involved }(\geq 50 \%)^{*}\end{array}$ & 90 & 91 \\
0 & 42 & \\
1 & 19 & 12 \\
2 & 15 & 10 \\
3 & 21 & 15 \\
LM & 4 & 3 \\
Systolic pressure (mm Hg) & $(\mathrm{n}=748)$ & $(\mathrm{n}=780)$ \\
& $136( \pm 24)$ & $145( \pm 27)$ \\
Diastolic pressure (mm Hg) & $(\mathrm{n}=748)$ & $(\mathrm{n}=778)$ \\
& $76( \pm 13)$ & $77( \pm 13)$ \\
LVEDP (mm Hg) & $(\mathrm{n}=704)$ & $(\mathrm{n}=742)$ \\
& $16( \pm 8)$ & $15( \pm 7)$ \\
Ejection fraction $(\%)^{*}$ & $(\mathrm{n}=651)$ & $(\mathrm{n}=698)$ \\
& $54( \pm 14)$ & $60( \pm 13)$ \\
\hline
\end{tabular}

LM, Left main; LVEDP, preangiographic left ventricular end-diastolic pressure.

Values are percentages unless otherwise indicated.

${ }^{*} p<0.001$.

except for a history of hypertension (or one of its sequelae, ECG evidence of left ventricular hypertrophy) in either sex. A history of smoking remained predictive in women only. Chest pain (unspecified) was more predictive in men than in women, but atypical pain syndromes were strongly negative predictors in both sexes. Previous myocardial infarction found on ECG increased the likelihood (odds ratio) of finding coronary disease in women more powerfully than all other factors. The next most powerful predictor was diabetes. The overall predictive values of these regression models were similar in both sexes but suggested greater sensitivity for applications in men (sensitivity $78 \%$, specificity $64 \%$, correct predictions $72 \%$ ) and greater specificity in women (sensitivity $54 \%$, specificity $86 \%$, correct predictions $74 \%)$.

To reassess the importance of a history of hypertension in our black patients, logistic regression models that included central aortic systolic and diastolic pressure measurements, both with and without patient age, were fitted. This was done because of a possibly significant and confounding increase in the prevalence of essential hypertension with age and because centrally measured pressures during sedation and angiography might reflect vascular compliance. When age was deleted from these models, a history of hypertension did gain significance $(p=0.0492)$, but increasing systolic $(p=0.0004)$ and decreasing diastolic $(p=0.0005)$ pressures (the picture of vascular aging or decreased compliance) became more significant independent predictors (model sensitivity $77 \%$, model specificity $66 \%$ ).

The following three additional subgroups were 
Table III. Univariate analysis for coronary artery disease in black men

\begin{tabular}{lcc}
\hline \multicolumn{1}{c}{ Variables } & $\begin{array}{c}C A D \\
(n=438)\end{array}$ & $\begin{array}{c}\text { No CAD } \\
(n=313)\end{array}$ \\
\hline Age (yr)* & $59( \pm 11)$ & $54( \pm 11)$ \\
BMI (kg/m $\left.{ }^{2}\right)$ & $28( \pm 5)$ & $28( \pm 6)$ \\
Hypertension & 71 & 66 \\
Diabetes* & 28 & 16 \\
Smoking (ever) & 64 & 59 \\
Family history & 27 & 25 \\
Lipid elevation* & 22 & 11 \\
History of infarction* & 40 & 12 \\
ECG evidence of infarction* & 35 & 9 \\
ECG evidence of LVH & 25 & 22 \\
Chest pain & 85 & 82 \\
Typical angina* & 80 & 62 \\
Atypical pain* & 6 & 20 \\
DOE or SOB & 35 & 39 \\
Congestive heart failure & 10 & 10 \\
Right dominance $\dagger$ & 92 & 87 \\
Systolic pressure (mm Hg) & $137( \pm 25)$ & $135( \pm 24)$ \\
Diastolic pressure (mm Hg) & $76( \pm 13)$ & $77( \pm 12)$ \\
LVEDP (mm Hg) & $17( \pm 8)$ & $14( \pm 7)$ \\
Ejection fraction $(\%) *$ & $52( \pm 15)$ & $58( \pm 13)$ \\
\hline
\end{tabular}

$B M I$, Body mass index; $C A D$, coronary artery disease; $D O E$, dyspnea on exertion; $L V H$, left ventricular hypertrophy; $L V E D P$, left ventricular end-diastolic pressure; $S O B$, shortness of breath.

Values are percentages unless otherwise indicated.

${ }^{*} p<0.001$.

$+p<0.05$.

Table IV. Univariate analysis for coronary artery disease in black women

\begin{tabular}{|c|c|c|}
\hline Variables & $\begin{array}{c}C A D \\
(n=306)\end{array}$ & $\begin{array}{l}\text { No } C A D \\
(n=478)\end{array}$ \\
\hline Age $(y r)^{*}$ & $62( \pm 10)$ & $57( \pm 11)$ \\
\hline BMI $\left(\mathrm{kg} / \mathrm{m}^{2}\right)$ & $29( \pm 6)$ & $30( \pm 7)$ \\
\hline Hypertension $\dagger$ & 82 & 73 \\
\hline Diabetes* & 49 & 25 \\
\hline Smoking (ever) ${ }^{*}$ & 45 & 32 \\
\hline Family history & 33 & 29 \\
\hline Lipid elevation $\dagger$ & 25 & 16 \\
\hline History of infarction* & 32 & 8 \\
\hline ECG evidence of infarction* & 23 & 2 \\
\hline ECG evidence of $\mathrm{LVH}$ & 21 & 18 \\
\hline Chest pain & 90 & 91 \\
\hline Typical angina $\uparrow$ & 81 & 71 \\
\hline Atypical pain* & 9 & 21 \\
\hline DOE or SOB & 38 & 43 \\
\hline Congestive heart failure $\dagger$ & 13 & 6 \\
\hline Right dominance & 91 & 92 \\
\hline Systolic pressure (mm Hg) & $148( \pm 28)$ & $144( \pm 26)$ \\
\hline Diastolic pressure $(\mathrm{mm} \mathrm{Hg})$ & $76( \pm 13)$ & $77( \pm 13)$ \\
\hline LVEDP (mm Hg) & $17( \pm 8)$ & $14( \pm 6)$ \\
\hline Ejection fraction $(\%)^{*}$ & $56( \pm 14)$ & $63( \pm 11)$ \\
\hline
\end{tabular}

$B M I$, Body mass index; $C A D$, coronary artery disease; $D O E$, dyspnea on exertion; $L V H$, left ventricular hypertrophy; $L V E D P$, left ventricular end-diastolic pressure; $S O B$, shortness of breath.

Values are percentages unless otherwise indicated.

${ }^{*} p<0.001$.

$\dagger p<0.01$.
Table V. Frequency distribution of disease severity in black men and women with established coronary artery disease

\begin{tabular}{ccc}
\hline Vessels involved & $\begin{array}{c}\text { Males } \\
(n=438)\end{array}$ & $\begin{array}{c}\text { Females } \\
(n=306)\end{array}$ \\
\hline 1 & $33 \%$ & $30 \%$ \\
2 & $25 \%$ & $26 \%$ \\
3 & $35 \%$ & $38 \%$ \\
Left main & $7 \%$ & $7 \%$ \\
\hline Overall $p=0.8438$. & &
\end{tabular}

Table VI. Stepwise logistic regression for coronary artery disease in black men $(\mathrm{n}=738)$

\begin{tabular}{|c|c|c|c|c|}
\hline Variable & Beta & $\mathrm{p}$ Value & Odds ratio & $95 \% C I$ \\
\hline Age & 0.043 & 0.0001 & 1.04 & $1.03-1.06$ \\
\hline Diabetes & 0.492 & 0.0203 & 1.64 & $1.08-2.48$ \\
\hline Lipids & 0.899 & 0.0003 & 2.46 & $1.51-3.99$ \\
\hline $\begin{array}{l}\text { History of } \\
\text { infarction }\end{array}$ & 1.135 & 0.0001 & 3.11 & $1.98-4.89$ \\
\hline $\begin{array}{l}\text { ECG evidence } \\
\text { of infarction }\end{array}$ & 1.340 & 0.0001 & 3.82 & $2.30-6.34$ \\
\hline Chest pain & 0.838 & 0.0004 & 2.31 & $1.45-3.69$ \\
\hline Atypical pain & -1.360 & 0.0001 & 0.26 & $0.15-0.44$ \\
\hline \multicolumn{5}{|c|}{ Removed by Backward elimination ( $p$ ) } \\
\hline \multicolumn{5}{|c|}{ Smoking (0.1326), LVH on ECG (0.2989) } \\
\hline \multicolumn{5}{|c|}{ Hypertension (0.5590), family history (0.9109) } \\
\hline \multicolumn{5}{|c|}{ Typical angina removed by colinearity with chest pain } \\
\hline \multicolumn{5}{|c|}{ Predicted probabilities and observed responses } \\
\hline \multicolumn{5}{|c|}{ Concordant $=78 \%$, Discordant $=21 \%$. } \\
\hline
\end{tabular}

$C I$, Confidence interval; $L V H$, left ventricular hypertrophy.

Table VII. Stepwise logistic regression for coronary artery disease in black women $(\mathbf{n}=760)$

\begin{tabular}{lcccc}
\hline \multicolumn{1}{c}{ Variable } & Beta & $P$ & $\begin{array}{c}\text { Odds } \\
\text { ratio }\end{array}$ & $95 \%$ CI \\
\hline Age & 0.049 & 0.0001 & 1.05 & $1.03-1.07$ \\
Diabetes & 1.031 & 0.0001 & 2.80 & $1.97-3.99$ \\
Smoking & 0.872 & 0.0001 & 2.39 & $1.65-3.47$ \\
Lipids & 0.667 & 0.0018 & 1.95 & $1.28-2.96$ \\
History of infarction & 0.861 & 0.0007 & 2.37 & $1.44-3.88$ \\
ECG evidence of infarction & 1.940 & 0.0001 & 6.96 & $3.18-15.21$ \\
Atypical pain & -0.811 & 0.0017 & 0.44 & $0.21-0.74$ \\
Removed by backward elimination ( $p$ ) & & \\
Hypertension (0.1517), family history (0.2890) \\
Chest pain (0.6060), LVH on ECG (0.6995) \\
Typical angina removed by colinearity with chest pain \\
Predicted probabilities and observed responses \\
Concordant = 79\%, Discordant = 21\% \\
\hline
\end{tabular}

$C I$, Confidence interval; $L V H$, left ventricular hypertrophy.

studied: patients without a history of myocardial infarction, those without ECG evidence of infarction, and those without either. In all three groups stepwise logistic regression failed to show that history of hypertension was a significant independent predictor of coronary artery disease (sensitivity $72 \%$ to $79 \%$, 
Table VIII. Comparison of coronary angiographic results in black men and white men in the Coronary Artery Surgery Study

\begin{tabular}{|c|c|c|c|c|}
\hline & $\begin{array}{c}H U H \\
(n=751)\end{array}$ & $\begin{array}{c}C A S S(B)^{*} \\
(n=363)\end{array}$ & $\begin{array}{c}C C H \dagger \\
(n=454)\end{array}$ & $\begin{array}{l}\text { CASS }(W)^{*} \\
(n=17,377)\end{array}$ \\
\hline Age (yr) & $57 \pm 11$ & $49 \pm 10$ & $54 \pm 9$ & $53 \pm 9$ \\
\hline Hypertension $\left(\frac{0}{0}\right)$ & 69 & 57 & 77 & 31 \\
\hline Diabetes $(\%)$ & 23 & 14 & 23 & 10 \\
\hline Smoking $(\%)$ & 62 & - & 74 & - \\
\hline Family history $(\%)$ & 26 & 30 & - & 41 \\
\hline Prior myocardial infarction $(\%)$ & 28 & 50 & 43 & 53 \\
\hline Angina $(0)$ & 72 & $63-82$ & 84 & $76-82$ \\
\hline \multicolumn{5}{|l|}{ Vessels $(\%)$} \\
\hline 0 & 42 & 47 & 37 & 20 \\
\hline 1 & 19 & 20 & 21 & 22 \\
\hline 2 & 15 & 14 & 18 & 26 \\
\hline 3 & 21 & 19 & 23 & 33 \\
\hline Left main & 4 & 2 & 5 & 9 \\
\hline
\end{tabular}

HUH, Howard University Hospital; CASS, Coronary Artery Surgery Study; $\mathrm{CCH}$, Cook County Hospital.

*Adapted from Maynard el al. ${ }^{5}$

†Adapted from Simmons et al. ${ }^{7}$

specificity $52 \%$ to $61 \%$ ). Although men and women without a prior myocardial infarction had significantly different proportions with unspecified chest pain (females $>$ males, $p<0.05$ ) and coronary artery disease (males $>$ females, $p<0.05$ ), they did not differ with regard to atypical or typical angina. In addition, $23 \%$ of patients with a history of myocardial infarction did not have significant coronary artery disease and $17 \%$ of patients with ECG evidence of infarction did not have coronary artery disease. Among those with both a history of myocardial infarction and ECG evidence of infarction, $9 \%$ did not have coronary artery disease.

\section{DISCUSSION}

In this series of patients, descriptive and univariate analyses for risk factors of coronary artery disease have shown what may be regarded as typical findings in black patients. There is an overall lower incidence of detectable disease in comparison with findings in either contemporaneous or historical white series ${ }^{24}$ but a positive correlation between the standard risk factors and the presence of coronary artery disease. The lower prevalence of detectable disease is particularly striking, because any stenosis $\geq 50 \%$ was considered significant. Although some have detected significant ethnic variations in susceptibility to various plasma lipid fractions, ${ }^{25}$ this could not be addressed in this retrospective review.

Coronary angiographic studies have not fully replicated population-based studies with regard to risk factors and markers for coronary artery disease; therefore angiographic comparisons of black and white ethnic groups may have questionable explanatory value. Furthermore, the entire Coronary Artery Surgery Study (CASS) registry contains only 573 black patients compared with 23,008 white patients. ${ }^{5}$ The small number of black patients also qualifies the findings and general applicability of most previous reports. In the CASS data analyzed by Maynard et al., ${ }^{5}$ black men, black women, and white women all had a greater prevalence of hypertension, diabetes, and congestive heart failure than white men but a lower prevalence of detectable coronary disease. It is noteworthy that white men in the CASS had the highest prevalence of typical angina, documented myocardial infarctions, and professional occupations. Black persons were significantly younger than their sex-matched white counterparts. Inasmuch as white men had the greatest prevalence of coronary artery disease in the CASS, we are tempted to conclude that there may be both sex- and race-specific differences affecting patient referrals for coronary arteriography. In reports that analyzed white patients only, ${ }^{26,27}$ hypertension was an important risk marker only in women or it failed to achieve independent significance by multivariate analyses. ${ }^{28}$ The early report by Pearson et al. ${ }^{29}$ found less coronary artery disease in blacks than whites but suggested that hypertension was a more important risk factor in blacks. The final analysis of their data in patients undergoing coronary arteriography ( 915 whites, 81 blacks) reported a cor relation between hypertension and disease severity in both black and white patients. ${ }^{2}$ Logistic regression 
Table IX. Comparison of coronary angiographic results in black women and white women in the Coronary Artery Surgery Study

\begin{tabular}{|c|c|c|c|c|}
\hline & $\begin{array}{c}H U H \\
(n=784)\end{array}$ & $\begin{array}{c}C A S S(B)^{*} \\
(n=210)\end{array}$ & $\begin{array}{c}C C H \dagger \\
(n=568)\end{array}$ & $\begin{array}{l}C A S S(W)^{*} \\
(n=5,631)\end{array}$ \\
\hline Age (yr) & $59 \pm 11$ & $48 \pm 9$ & $57 \pm 8$ & $54 \pm 9$ \\
\hline Hypertension $(\%)$ & 77 & 66 & 85 & 41 \\
\hline Diabetes $(\%)$ & 34 & 21 & 30 & 12 \\
\hline Smoking $(\%)$ & 37 & - & 45 & 一 \\
\hline Family history $(\%)$ & 31 & 43 & - & 51 \\
\hline Prior myocardial infarction $(\%)$ & 18 & 33 & 19 & 32 \\
\hline Angina $(\%)$ & 75 & $47-88$ & 88 & $64-85$ \\
\hline \multicolumn{5}{|l|}{ Vessels (\%) } \\
\hline 0 & 61 & 67 & 58 & 55 \\
\hline 1 & 12 & 10 & 14 & 17 \\
\hline 2 & 10 & 11 & 14 & 15 \\
\hline 3 & 15 & 12 & 14 & 15 \\
\hline Left main & 3 & 2 & 3 & 4 \\
\hline
\end{tabular}

Abbreviations as in Table VIII

*Adapted from Maynard et al. ${ }^{5}$

+Adapted from Simmons et al. ${ }^{7}$

analysis involving 6316 white and only 278 black patients reported by Oberman and $\mathrm{Cutter}^{3}$ suggested that hypertension was correlated with advanced (i.e., two or more vessels) disease in white but not black persons. Their models did not include available cholesterol information, which could have altered the relative importance of independent predictors. The recent report by Simmons et al. ${ }^{7}$ contained a much larger number of black patients $(N=1022)$, who were characterized as from a lower socioeconomic strata but with essentially the same findings. Although they reported a uniquely high incidence of triple-vessel disease among those with established coronary artery disease, this may be a variance resulting from their method of calculating multivessel disease (see Methods). Categories of minimal disease should probably be differentiated from completely "normal" arteriograms by adopting a more continuous scale such as the "occlusion score" proposed by Rowe et al..$^{30}$ and modified by Freedman et al. ${ }^{8}$ Freedman's study also found less coronary artery disease in black men ( $\mathrm{n}=169 ; 56 \%$ with coronary artery disease) as compared with white men $(n=4722 ; 70 \%$ with coronary artery disease) undergoing coronary arteriography, despite an equal prevalence of hypertension ( $40 \%$ vs $39 \%)$ and acute myocardial infarction ( $48 \%$ vs $8 \%$ ), a significantly higher prevalence of diabetes in black patients $(13 \%$ vs $8 \%)$, and similar median ages (54 years vs 55 years). Blacks also had more $(78 \%$ vs $73 \%$ ) chest pain overall than whites.

The series of patients reported here from Howard University Hospital adds additional weight to what may be considered a secondary method for analyzing risk factors for coronary artery disease or for extrapolating conclusions regarding the incidence or prevalence of disease in the general population. The seeming superior sensitivity of predicting coronary disease in women and the greater specificity of predicting coronary disease in men that resulted from the regression models may indicate substantial sex differences in regard to how patients were selected for coronary angiography. For example, more men than women may have been referred for angiography after positive noninvasive testing, effecting a lower false positive outcome. There was also a significantly greater proportion of men with the strongest independent predictors of coronary artery disease (prior myocardial infarction based on history or ECG).

The overall results also suggest that a history of hypertension may be overrated as a risk marker for coronary artery disease in black patients undergoing coronary angiography and that in spite of the increased prevalence of hypertension in blacks, it is only a modestly causative factor in proximal coronary stenoses. Similar findings in patients with no prior history or ECG evidence of myocardial infarction add further weight to this suggestion. Such conclusions can only be regarded as tentative, given the retrospective nature of the study and the fact that there were no indications of the severity or duration of hypertension as estimated by onset of illness, medication history, or left ventricular mass measurements.

These findings are not a refutation of the wealth of data showing that hypertension results in a variety of 
severe structural and hemodynamic derangements and eventuates in the premature death of afflicted patients. It is likely that the effects of hypertension on the heart make it more susceptible to modest forms of coronary artery disease or other types of ischemia that cannot be detected by routine angiography.

Tables VIII and IX display comparative findings from the largest series of black patients undergoing coronary angiography in comparison with data from white patients in the CASS. Although purely descriptive, the information suggests that in spite of an equal or greater prevalence of certain risk factors, blacks are less frequently found to have significant coronary artery disease. These studies are uniform in detecting smaller proportions of black patients who would normally be referred for angioplasty or bypass surgery. Numerous selection biases for coronary angiography may explain these apparent ethnic differences. Given the highly predictive power of a prior myocardial infarction in relation to the angiographic findings found in the Howard University Hospital data discussed previously, the greater frequency of prior myocardial infarction in white patients in the CASS (male and female) may be a partial reasonable explanation. The consistently larger female-to-male ratio within the black population as compared with white patients undergoing angiographic studies may reflect other medical and social phenomena that are not addressed in this report.

Other potential sources of error in this data set are numerous. Missing reports may contain an unknown biased subgroup. The reliance of an argument from silence to claim the absence of any particular risk factor should underestimate the true prevalence of risk factors. The presence of hypertension may represent a blending of mildly and severely affected persons. The printed catheterization reports from which the data were derived are the product of at least 15 different attending cardiologists and nonuniform methods of judging the degree of stenosis. Our somewhat liberal method of judging significant stenosis as $\geq 50 \%$, as employed by Oberman et al., ${ }^{3}$ should overestimate the severity of disease and makes the high negative coronary artery disease rate in our black patients more striking when compared with other reported series in whites. There are important and perhaps severe limitations in the general applicability of a retrospective study of angiographic findings in relation to risk factors. ${ }^{31,32}$ The resulting misclassification of control subjects is lucidly explored by Sharrett et al. ${ }^{32}$ and evokes caution in the interpretation of our results.

We thank Ms. Juanetta T. Swann for expert secretarial assistance in preparation of the manuscript.

\section{REFERENCES}

1. Peniston RL, Randall OS. Coronary artery disease in black Americans 1920-1960: the shaping of medical opinion. IJ Natl Med Assoc 1989;81:591-600.

2. Pearson TA. Risk factors for arteriographically defined CAD [dissertation]. Baltimore: Johns Hopkins University, 1983:274.

3. Oberman A, Cutter G. Issues in the national history and treatment of coronary heart disease in black populations: surgical treatment. AM HEART J 1984;188:688-94.

4. Sue-Ling K, Watkins LO. Coronary arteriographic findings in black veterans [Abstract]. Circulation 1984;70(suppl II): 410.

5. Maynard C, Fisher LD, Passamani ER, Pullum T. Blacks in the Coronary Artery Surgery Study: risk factors and coronary artery disease. Circulation 1986;74:64-71.

6. Carryon P, Matthews MM. Clinical and coronary arteriographic profile of 100 black Americans: focus on subgroup with undiagnosed suspicious chest discomfort. J Natl Med Assoc 1987;79:265-72.

7. Simmons BE, Castaner A, Campo A, Ferlinz J, Mar M, Cooper R. Coronary artery disease in blacks of lower socioeconomic status: angiographic findings from the Cook County Hospital Heart Disease Registry. AM HEAR'T J 1988;116: 90-7.

8. Freedman DS, Gruchow HW, Manley JC, Anderson AJ, Sobocinski KA, Barboriak JJ. Black/white differences in risk factors for arteriographically documented coronary artery disease in men. Am J Cardiul 1988;62:214-9.

9. Gillum RF. Coronary heart disease in black populations. I. Mortality and morbidity. AM HEART J 1982;104:839-51.

10. Cardiovascular and Cerebrovascular Diseases in Black Americans. Report of the Secretary's Task Force on Black and Minority Health. Volume IV: Cardiovascular and Cerebrovascular Disease, Part I. Washington, DC: United States Department of Health and Human Services, January 1986:3-54.

11. Gillum RF, Grant CT. Coronary heart disease in black populations. II. Risk factors. AM HEART J 1982;104:852-64.

12. Pearson TA. Coronary arteriography in the study of the epidemiology of coronary artery disease. Epidemiol Rev 1984; 6:140-66.

13. Hagstrom RM, Federsteil CF, Ho WY. Incidence of myocardial infarction and sudden death from coronary heart disease in Nashville, Tennessee. Circulation 1971;44:884-90.

14. Kuller L, Perper J, Cooper M. Demographic characteristics and trends in atherosclerotic heart disease mortality: sudden death and myocardial infarction. Circulation 1975;52(suppl III): $1-15$

15. Weisse AB, Abiuso PD, Third IS. Acute myocardial infarction in Newark, New Jersey: a study of racial incidence. Arch Intern Med 1977;137:1402-5.

16. Cooper R, Simmons BF. Hypertension as a cause of lower than expected death rates from coronary artery disease among blacks. Clin Cardiol 1989;12(suppl IV):9-12.

17. Peniston RL, Miles N, Mehta V, et al. Chest pain: coronary artery disease and hypertension [abstract]. Third International Interdisciplinary Conference on Hypertension in Blacks. Baltimore, Md:: April 21-24, 1988.

18. Brush JE, Cannon RO, Schenke BA. Angina due to coronary microvascular disease in hypertensive patients without left ventricular hypertrophy. N Engl J Med 1988;319:1302-7.

19. Wenneker MB, Epstein AM. Racial inequalities in the use of procedures for patients with ischemic heart disease in Massachusetts. JAMA 1989;261:253-7.

20. Ford E, Cooper R, Castaner A, Simmons B, Mar M. Coronary arteriography and coronary bypass survey among whites and other racial groups relative to hospital-based incidence rates for coronary artery disease: findings from NHDS. Am J Public Health 1989;79:437-46.

21. Hannan EL, Kilburn H, O'Donnell JF, Lukacik G, Shields EP. Interracial access to selected cardiac procedures for patients hospitalized with coronary artery disease in New York State. Med Care 1991;29:430-41. 
22. Wenneker MB, Weisman JS, Epstein AM, The association of payer with utilization of cardiac procedures in Massachusetts. JAMA 1990;264:1255-60.

23. Harrell FE, Peterson B. The Logist procedure. SUGI Supplemental Library Guide, version 6 edition. Gary, N.C.: SAS Institute, Inc., 1988.

24. Cooper RS, Gbali JK. Coronary heart disease: Black-white differences. In: Saunders E, ed. Cardiovascular disease in blacks. Curdiovasc Clin 1991;21:205-25.

25. Lewis CF, Raczynski JM, Oberman A, Cutter GR. Risk factors and the natural history of coronary heart disease in blacks. In: Saunders E, ed. Cardiovascular disease in blacks. Cardiovasc Clin 1991;21:29-45.

26. Holmes DR, Elnebock LR, Frye RL, Kottke BA, Ellefson RD. Association of risk factor variables and coronary artery disease documented with angiography. Circulation 1981;63:293-9.

27. Vlietstra RE, Frye RL, Kronmal RA, Sim DA, Tristan FE, Killip $T$. Risk factors and angiographic coronary artery disease: a report from the Coronary Artery Surgery Study (CASS). Circulation 1980;62:254-61.

28. Anderson AJ, Barboriak JJ, Rimm AA. Risk factors and angiographically determined coronary occlusion. Am J Epidemiol 1978;107:8-14.

29. Pearson TA, Bulkley BH, Kwiterovich PO, Achuff SC, Gordis L. Anatomically defined coronary disease in blacks: importance of hypertension as a risk factor [Abstract]. Circulation 1979;59-60(suppl II): 14

30. Rowe GG, Thomsen JH, Stenlund RR, McKenna DH, Sialer $\mathrm{S}$, Corliss RJ. A study of hemodynamics and coronary blood flow in men with coronary artery disease. Circulation 1969; 39:139-48.

31. Crouse III JR, Thompson CJ. An evaluation of methods for imaging and quantifying coronary and carotid lumen stenosis and atherosclerosis. Circulation 1993;87(suppl II):17-33.

32. Sharrett AR. Invasive versus noninvasive studies of risk factors and atherosclerosis. Circulation 1993;87(suppl II):48-53.

\section{Improved detection of transient myocardial ischemia by a new lead combination: Value of bipolar lead Nehb D for Holter monitoring}

The investigations of ST-segment changes by Holter monitoring demonstrate asymptomatic and symptomatic episodes of myocardial ischemia, which may occur during daily activities. One factor, which is of great importance for the detection of silent myocardial ischemia during ambulatory monitoring, is the combination of the leads. Former studies showed that the analysis of two channels alone may not adequately detect silent myocardial ischemia. We therefore used a three-channel ambulatory ECG monitoring system with a new lead combination. The Holter monitoring results were correlated with the distribution of coronary stenosis detected by coronary angiography. In 54 patients with single coronary vessel disease and ischemic ST-segment depressions during exercise testing, standard Holter lead combination CM2/CM5 was extended by a bipolar Nehb D-like lead. Lead combination CM2/CM5 identified 23 patients $(43 \%)$ with ST-segment depressions (total number of ischemic episodes $=372$ ). Additional Nehb D-like lead identified 30 patients (55\%) with ST-segment depressions (total number of ischemic episodes $=1048$ ). The combination of leads CM2/CM5 and Nehb D raised the number of patients with documented ST-segment depressions to 33 of $54(61 \%)$. Lead Nehb D showed the highest sensitivity for the detection of inferior wall ischemia (stenosis of the right coronary artery); nevertheless, this lead may not be regarded as specific for ST-segment alterations only caused by inferior wall ischemia. The correlation of ischemic ST-segment depressions during exercise testing (classified as anterior, inferior, or anterior and inferior type of ischemia) and documented ST-segment changes in the different Holter leads underline these results. A control group of $\mathbf{4 0}$ healthy volunteers demonstrated the high specifity of this new lead combination. In comparison with the standard lead combination CM2/CM5 for the detection of ST-segment changes, lead combination CM2/CM5 extended by a bipolar Nehb D lead is more sensitive for the detection of ST-segment alterations by Holter monitoring. (AM HEART J 1994;127:559-66.)

Hans-H. Osterhues, MD, Thomas Eggeling, MD, Matthias Kochs, MD, and Vinzenz Hombach, MD Ulm, Germany

From the Department of Cardiology, University of Ulm, Germany Received for publication January 8, 1993; accepted July 15, 1993. Reprint requests: Dr. Hans-H. Osterhues, MD, Department of Cardiology, University of Ulm, Robert-Koch-Str. 8, D-89081 Ulm, Germany.

Copyright 1994 by Mosby-Year Book, Inc.

$0002-8703 / 94 / \$ 3.00+0 \quad \mathbf{4} / \mathbf{1} / \mathbf{5 1 7 9 2}$
With the technical development of ambulatory (Holter) ECG for the accurate measurement of STsegment alterations, it was possible to detect silent or asymptomatic episodes of myocardial ischemia. It is a well known fact that exercise ECG, thallium scin- 